\title{
LA IGLESIA DE TOLEDO EN LA EDAD MEDIA: ORGANIZACIÓN INSTITUCIONAL Y FORMAS DE VIDA RELIGIOSA. ESTADO DE LA CUESTIÓN: ARCHIVOS Y DESCRIPCIÓN DE MANUSCRITOS
}

\author{
POR \\ ENRIQUE TORIJA RODRÍGUEZ ${ }^{1}$ \\ Departamento de Historia Medieval. Universidad Complutense de Madrid
}

RESUMEN:

Este trabajo presenta un estado de la cuestión sobre el estudio del arzobispado de Toledo en la Edad Media, sin referirnos al resto de sus diócesis sufragáneas, tras la conquista de esta ciudad en 1085 por el rey Alfonso VI de León y Castilla. Incluye los principales archivos (en Toledo, en España y en el mundo) necesarios para abordar su estudio así como un apartado con la descripción de manuscritos acerca de la Iglesia de Toledo en la Edad Media.

PALABRAS CLAVE: Archivos y manuscritos medievales: Metodología de la historia religiosa; Arzobispado de Toledo; Religiosidad medieval; Instituciones medievales de la Iglesia.

\section{THE CHURCH OF TOLEDO IN MIDDLE AGES: INSTITUTIONAL ORGANIZATION AND RELIGIOUSNESS. STATE OF THE ART: ARCHIVES AND MANUSCRIPTS}

\begin{abstract}
:
This study presents an State of the Art about the Archdiocese of Toledo in the Middle Ages after the conquest of this town in 1085 by King Alfonso VI of León and Castile. It includes the principal archives (placed in Toledo, placed in Spain or placed at the world) needed to approach its study and it has a section with the description of manuscripts about the Church of Toledo in the Middle Ages.
\end{abstract}

KEY WORDS: Archives and medieval manuscripts; Methodology of religious history; Archdiocese of Toledo: Medieval religiousness; Medieval institutions of Catholic Church.

CÓMO CITAR ESTE ARTículo / CITATION: Torija Rodríguez, E. (2017): «La Iglesia de Toledo en la Edad Media: organización institucional y formas de vida religiosa. Estado de la cuestión: archivos y descripción de manuscritos». Hispania Sacra 69, 139 : 31-47. doi: 10.3989/hs.2017.003

$\begin{array}{ll}\text { Recibido/Received } & 19-05-2012 \\ \text { Aceptado/Accepted } & 04-04-2016\end{array}$

\section{INTRODUCCIÓN}

La importancia terrenal de la Iglesia de Toledo en el pasado, y más concretamente para el período medieval, ha afectado enormemente a la investigación de su funcionalidad eclesiástica, a veces negativamente: su relevancia política ha desviado a muchos hacia ese campo. Además, la tarea de realizar el estudio sobre una diócesis con un territorio amplísimo ha debido desalentar a muchos, sin olvidar que, como metropolitano, su jurisdicción abarcaba una extensión mucho mayor.

\footnotetext{
${ }_{1}$ enrique.torija@ucm.es / ORCID iD: http://orcid.org/0000-0003-3859-9699
}

Pero no todo son contratiempos, pues estas dificultades también la convierten en un objetivo interesante. El mayor atractivo radica en su idiosincrasia única en la Historia de España. Su carácter de primada le da una triple dimensión para el estudio que no existe en otra diócesis de la Península Ibérica: como primado de las Españas, como metropolitano de una provincia eclesiástica y como arzobispo de su archidiócesis.

La historiografía tradicional ha reducido la Historia de la Iglesia a la de los sucesivos papas, siendo incompleta, ya que la etimología de la palabra «iglesia» hace referencia al conjunto de los fieles reunidos en torno a un dogma espiritual. Fieles que incluyen a los jerarcas de la institución, pero también a los seguidores. Elaborar un estudio sobre 
el grupo sacerdotal y la jerarquía puede hacerse basándose en la documentación que nos ofrecen datos económicos e institucionales, pero para el pueblo fiel debemos acercarnos a la formas de piedad y devoción, que es lo que les pone en relación con su fe, y para el período medieval es útil para este fin utilizar tanto los sínodos diocesanos como los catecismos.

Geográficamente nos moveremos por el espacio cambiante de la archidiócesis toledana durante la Edad Media: en su final comprendía las actuales provincias de Toledo, Ciudad Real, Madrid y parte de las de Albacete, Guadalajara, Jaén, Cáceres y Badajoz. Como primado y metropolitano se estudiarán aspectos que alcanzan otras zonas geográficas, pero a un nivel jurisdiccional y relacional.

Finalmente, de su delimitación temporal cabe mencionar la facilidad con la que hemos decidido situar el comienzo: 1086, año de la restauración de la sede episcopal tras la conquista de Toledo un año antes. Dicha restauración ocasiona el nacimiento de una nueva Iglesia de Toledo de influencia romana y franca que rompe con la anterior de tradición visigótica, mantenida en época de la ocupación musulmana por la comunidad mozárabe.

El problema viene a la hora de poner el límite final, no exclusivo de nuestro trabajo, sino de la tradicional polémica historiográfica de división de las edades: poner límites a la Edad Media. Teniendo en cuenta que la reforma eclesiástica llegó antes a España que al resto de Europa en gran parte auspiciada por un arzobispo de Toledo, el cardenal Cisneros, ponemos el límite en el gobierno arzobispal de su antecesor, el cardenal Mendoza.

Conocer los archivos a los que podemos acudir, y describir algunos de sus fondos principales, es sumamente interesante para planificar de antemano cualquier estudio. Por diversos avatares históricos España goza de una cierta centralización archivística entre el Archivo Histórico Nacional y la Biblioteca Nacional Española, entre otros motivos gracias al proceso desamortizador decimonónico. Esto ha condicionado que otros archivos sean menos conocidos, y por tanto menos explotados con fines de investigación. Para Toledo y su Iglesia es fundamental el Archivo y la Biblioteca Capitular de la Catedral de Toledo; sin duda el centro de la investigación.

El comentado proceso desamortizador que sufrió la Iglesia española en el siglo XIX hizo que parte de los fondos que hasta el momento estaban en manos de diversas instituciones eclesiásticas pasasen bajo el control directo del Estado. De esta circunstancia nació el Archivo Histórico Nacional.

La Biblioteca Nacional de Madrid también es otro de los lugares fundamentales: de forma específica para Toledo es más que interesante la parte denominada como los «papeles de Burriel».

El Archivo Secreto Vaticano ha sido poco utilizado por la historiografía española para completar sus investigaciones, y en muchos casos sin llegar a establecerse bien la relación existente entre los temas eclesiásticos hispanos y los generales o los de la política pontificia. ${ }^{2}$

2 Este «error» o falta por parte de la historiografía hispana ya era comentado en unos de sus estudios por parte de los profesores Ladero Quesada y Nieto Soria (1988: 126).
Existen otros archivos pero cuyos fondos tratan el tema de la Iglesia toledana medieval de forma más tangencial. Es el caso del Archivo Diocesano de Toledo, cuyos fondos ya abarcan la Edad Moderna y no la Media, o el Archivo de la Diputación Provincial de Toledo, con los datos de las fundaciones benéficas y asistenciales, al pasar esas competencias de la Iglesia, su fundadora medieval, al Estado en época decimonónica.

Mencionaremos aquellos catálogos, índices u otros elementos descriptivos de los mismos que, ya publicados, puedan convertirse en herramientas útiles de búsqueda. Cabe mencionar, de forma general, el Censo-Guía de archivos creado por el Ministerio de Cultura español ${ }^{3}$ y la Guía de los Archivos de la Iglesia en España ${ }^{4}$ por parte de la Asociación de Archiveros de la Iglesia en España como punto de partida. También se hará relación de aquellas colecciones documentales de fuentes publicadas de los archivos mencionados.

\section{ARCHIVOS PARA EL ESTUDIO DE LA IGLESIA DE TOLEDO}

\section{Archivo y Biblioteca Capitular de la Catedral de Toledo}

Para todo estudio sobre la Iglesia toledana este Archivo y Biblioteca ${ }^{5}$ es sin duda el lugar fundamental para buscar información. ${ }^{6}$

Los elementos descriptivos del Archivo han sido llevados a cabo por los últimos canónigos-archiveros de la institución. El más antiguo es un breve trabajo de Juan Francisco Rivera Recio, que describe los diferentes fondos del mismo. ${ }^{7}$ Más reciente y que complementa al anterior, es la Guía del Archivo y Biblioteca Capitulares de la Catedral de Toledo obra del actual archivero, Ángel Fernández Collado. ${ }^{8}$

Entre lo publicado existen algunos catálogos sobre los fondos medievales de los mismos que resultan de interés y ayuda al investigador. El primero de ellos es la publicación Manuscritos jurídicos medievales de la Catedral de Toledo, ${ }^{9}$ por parte de Antonio García García y Ramón Gonzálvez Ruiz.

Sobre los manuscritos litúrgicos de la Catedral trata la obra de José Janini y en colaboración con el archivero Ramón Gonzálvez Ruiz, Manuscritos litúrgicos de la Catedral de Toledo. ${ }^{10}$ Incluye libros de liturgia latina y libros de horas hasta alcanzar una cifra que ronda los 250 volúmenes. Los códices de Toledo, trasladados a Madrid, han sido descritos en Manuscritos litúrgicos de la Biblioteca Nacional. ${ }^{11}$

3 Se puede consultar desde la página web del Ministerio de Cultura. http://censoarchivos.mcu.es/

4 Martí Bonet (dir.) 1985.

5 Para conocer la historia y evolución de la Biblioteca Capitular resulta más que recomendable la consulta de la Tesis doctoral del antiguo archivero de la Catedral: Gonzálvez Ruiz 1997. Una versión más reducida de la historia de la Biblioteca puede consultarse en la introducción de Janini y Gonzálvez 1977. Respecto al Archivo, es de interés consultar la introducción, a cargo de Ramón Gonzálvez en Hernández 1996.

6 De su importancia ya nos hablaba María José Lop Otín (2002) al afirmar que la documentación allí contenida había supuesto el $90 \%$ de su investigación.

7 Rivera Recio 1950.

8 Fernández Collado 2007.

9 García García y Gonzálvez Ruiz 1970.

10 Janini y Gonzálvez 1977.

11 Janini y Serrano 1979. 
Como catálogo general de las obras impresas de la Biblioteca se tiene publicado por parte del personal del Archivo Catálogo de impresos de la Catedral de Toledo. ${ }^{12} \mathrm{~A}$ su vez, de los fondos de la Capilla parroquial de San Pedro de la Catedral se tiene un Catálogo del Archivo de la capilla de San Pedro en la Catedral de Toledo. ${ }^{13}$

De la Obra y Fábrica se ha publicado un catálogo que aspiraba a ser el primer tomo de una serie que abarcaría todos sus fondos. El mencionado catálogo comprende la documentación desde el siglo XIV, con los primeros fondos, hasta el siglo XVI; realizado por Carmen Torroja Menéndez, lleva por título Catálogo del Archivo de la Obra y Fábrica de la Catedral de Toledo. ${ }^{14}$

Respecto a las colecciones documentales publicadas, destaca la gran obra de Ángel González Palencia relativa a documentos «mozárabes»: unos 875 pergaminos de este tipo, comprendidos entre 1124 y 1678, que fueron incautados de la Catedral en época de la desamortización y llevados al Archivo Histórico Nacional. Entre 1925 y 1930 el citado autor publicó los documentos de época medieval en 4 volúmenes, siendo el primero un estudio sobre los mismos, en su obra Los mozárabes de Toledo en los siglos XII y XIII. ${ }^{15}$

También de una importancia enorme es la obra Los cartularios de Toledo. Catálogo documental ${ }^{16}$ de Francisco J. Hernández, que apareció en 1985 y que reproduce los resúmenes de 702 documentos incluidos en ocho cartularios.

El trabajo de José Antonio García Luján Privilegios reales de la Catedral de Toledo (1086-1462)17 de los primeros años de la década de los 80 estudia los privilegios reales conservados en la Catedral Primada. Además del estudio paleográfico y diplomático, como centro de su investigación y que ocupa su primer volumen, es de interés el segundo volumen, con la colección documental y transcripción de los mismos.

Más recientemente se han publicado los diferentes Documentos del archivo de la Catedral de Toledo en escritura visigótica, ${ }^{18}$ por parte de José María Fernández Catón.

En 1950 Rivera Recio estructuraba el Archivo de la siguiente forma: Archivo General, Fondos de Apuntación, Archivo de la Sala Capitular, Archivo de la Obra y Fábrica, Archivo de Mayordomía, Expedientes de limpieza de sangre y Fondos documentales de la Biblioteca Capitular. ${ }^{19}$ Para época medieval y para el estudio que se desea realizar son de interés: los Fondos de Apuntación, con la documentación producida por el apuntador, encargado de la asistencia de los eclesiásticos a las diferentes funciones de iglesia; el Archivo Capitular, generado por la Secretaría Capitular que recibía, despachaba y custodiaba documentos relativos al personal, régimen y gobierno de la Catedral; el Archivo de la Obra y Fábrica, que guarda la documentación relacionada con la construcción, conservación y ornamentación del edificio catedralicio; y el Fondo de Mayordomía, con la documentación económica y administrativa de los mayordomos del templo.

\footnotetext{
12 Fernández Collado, Rodríguez González y Castañeda Tordera 2009.

13 Fernández Collado, Rodríguez González y Castañeda Tordera 2007.

14 Torroja Menéndez 1977.

15 González Palencia 1926-1930.

6 Hernández 1996.

7 García Luján 1982.

8 Fernández Catón 1989.

9 Rivera Recio 1950.
}

Del Archivo Capitular se tiene un Repertorio Universal del Archivo sin publicar; en la Catedral disponen para uso del investigador de una fotocopia del original del XVIII, elaborado por los padres Mecaloeta y Sarmiento en 1727; no todos los documentos se siguen conservando hoy en día en el Archivo por diversos motivos. Dividido en cajones, cada cajón contiene doce arquetas, con una designación alfanumérica. Cada arqueta tiene un número para identificarlo y los cajones una letra. El índice contiene entradas para buscar por topónimos o temas. ${ }^{20}$ También está a disposición de los investigadores un fichero, no temático, sino cronológico, desde 1086 en adelante.

El Archivo de Obra y Fábrica ${ }^{21}$ realmente comprende varios de los apartados que menciona Rivera Recio en su guía: la Obra y Fábrica en sí, los Fondos de Apuntación y los de Mayordomía. En los Fondos de Apuntación hay dos series que comprenden de 1436 a 1536. En ellos se anotan las asistencias de los canónigos, racioneros y capellanes y lo que cada uno percibe por ello. Estas series son la de Maitines, con la asistencia de maitines, semanas de misa, de cantoría, epístola y evangelios,... y la de Caridades con la asistencia a misas de difuntos, procesiones, enterramientos y exequias,... y lo que le corresponde a cada uno de las caridades o limosnas que se deja en los testamentos.

En los Fondos de Mayordomía tenemos los libros de Refitor, Protocolos, Registro de Escrituras, Subsidio y Vestuario. El Refitor era la oficina que administraba los bienes del cabildo y su principal encargado era el refitolero. Sus partes más importantes son las de Posesiones, Gallinas, Granero, Vestuario y el propio de Refitor, que contiene Cargos y Data, Carta Cuenta, Manual y Mayor. Esta serie es fundamental para estudiar los bienes inmuebles del Cabildo. El reparto del dinero se anota en los libros de Presencias de Tercios. Se conservan 26 libros de Protocolos anteriores a 1500. Los Registros de Escrituras tienen en su mayor parte los contratos de arrendamientos de las posesiones. También aparecen los diferentes contratos con los artistas que trabajan por y en la Catedral. Las rentas eclesiásticas cedidas a la Corona por concesión papal las encontramos en el Subsidio. De esta serie son también los libros de Congregaciones de Iglesias, con las reuniones del clero castellano-leonés para ver qué parte del subsidio le toca a cada diócesis del reino, y los de Finiquitos, con las aceptaciones por parte del Cabildo de Toledo de las cuentas que tiene que entregar al subsidio. Finalmente en Vestuario se tienen los diezmos de panes $y$ vinos que eran arrendados al mejor postor y que se reparten entre los canónigos asistentes al coro.

De los Fondos de Obra y Fábrica se puede decir que el más importante es el Libro de la Obra. También están las series de Excusados, Títulos de Posesiones y de Tributos. El dinero para la construcción del templo venía de los excusados o diezmos. Durante el siglo xv el que recibe las rentas y

\footnotetext{
20 Se encuentran divididos en los cajones de la siguiente forma: Cajón A: De la A hasta la C (canónigos).

Cajón E: De la C (Capellanes del Choro) hasta la C (Catedráticos).

Cajón I: De la C (Cazalegas) hasta la D.

Cajón O: De la E hasta la J.

Cajón V: De la L hasta la N.

Cajón X: De la O hasta la S (Sagrario).

Cajón Z: De la S (Sal y salinas) hasta la Z.

${ }^{21}$ La división en series y libros es la realizada por Carmen Torroja en su catálogo mencionado.
} 
rinde cuentas de los gastos es el Obrero. Hay, en este Libro de la Obra, una partida llamada Danzas y autos con lo que pagaba la Obra para contribuir al esplendor la fiesta del Corpus Christi.

De otras partes del Archivo de Obra y Fábrica hay varios libros, como los de Capellanías y obras pías, que se hicieron en la catedral desde su fundación, y también los libros de visitas; los relativos al Sagrario o tesoro de la Catedral; los denominados como Extraordinario y Albaquías, con los gastos fuera del Refitor; diversas Cuentas de Particulares, de seglares o canónigos con el gasto de sus casas y cuentas con los criados, amas y escuderos; las cuentas de Varios Conceptos, con un interesante libro titulado "Libro de cuentas del cabildo de la Santa Iglesia de Toledo» con los gastos del Corpus de 1493 a 1510; los libros de Oficios y Cargos; libros referentes a diversas ciudades, pueblos o lugares, muchos de ellos por pertenecer al Cabildo; y libros de varias instituciones.

\section{Biblioteca Nacional de Madrid}

Muchos de los papeles y códices incautados a la Catedral de Toledo en el siglo xIX fueron a parar a la Biblioteca Nacional ${ }^{22}$. Pero con anterioridad, y de gran interés para un estudio sobre la Iglesia de Toledo en la Edad Media, está la incautación que la Corona hizo de los documentos de los jesuitas expulsados en 1767. Esta incautación pasó a formar parte de los fondos de la entonces Biblioteca Real que es la génesis de la actual Biblioteca Nacional. Entre ellos se encuentran los conocidos como "papeles de Burriel», con las copias que este ilustrado jesuita hizo de los documentos que había en la Catedral de Toledo. En estos papeles hay más de 2000 copias de documentos y privilegios, con bulas y diplomas que hacen referencia a la primacía, constituciones sinodales y conciliares, estatutos capitulares, vidas de prelados, cartas entre los arzobispos y su cabildo,...

Para conocer sus fondos es indispensable el uso del Índice de Manuscritos, ${ }^{23}$ los llamados papeles de Burriel se sitúan en las signaturas comprendidas entre los números 12985 y 13136.

Como ya se ha mencionado, los libros incautados a la Catedral se encuentran en la Biblioteca Nacional. Entre ellos figuran tratados espirituales y libros litúrgicos, utilísimos para el estudio de la religiosidad toledana. Algunos de los catálogos sobre los mismos ya han sido mencionados, como el realizado por José Janini y José Serrano. Existe algún otro, con errores e incompleto, pero que evidencian la riqueza de la biblioteca toledana. ${ }^{24}$

\section{Archivo Histórico Nacional}

Los fondos documentales del Archivo Histórico Nacional $^{25}$ se estructuran en un cuadro de clasificación que,

22 Parte de sus fondos se encuentran digitalizados y accesibles online desde su catálogo: http://www.bne.es/es/Catalogos/

23 Índice General de Manuscritos. 13 tomos. Biblioteca Nacional. Disponible digitalmente. http://www.bne.es/es/Micrositios/Guias/ Inventario_Manuscritos/

24 Octavio de Toledo 1903.

25 Sin duda es de enorme utilidad el acceso a sus fondos digitalizados, que pueden consultarse on-line a través del portal PARES: http:// pares.mcu.es/ dada su diversidad, se articula en cinco grandes apartados: Instituciones del Antiguo Régimen, Instituciones Contemporáneas, Instituciones Eclesiásticas, Archivos Privados y Colecciones.

El fondo de las Instituciones Eclesiásticas, cuya documentación es la más antigua (S. IX-XIX), ingresó en el Archivo como consecuencia de las leyes desamortizadoras. Para nuestro trabajo es más interesante la sección de Clero Secular, 96 fondos de catedrales (con documentación que va del siglo IX al XIX); 2011 de iglesias parroquiales, colegiatas y ermitas (con documentación que va del siglo $\mathrm{x}$ al $\mathrm{XIX}$ ); y los de Instituciones Pías y Asistenciales con 110 fondos de hospitales (documentación del XII al XIX). Esta copiosa documentación se custodia en las secciones de Clero, Órdenes Militares, Códices y Cartularios y Sigilografía.

Entre los elementos descriptivos fundamentales de la Sección de Clero, los más interesantes para nosotros son el Catálogo de instrumentos descripción de la Sección de Clero $^{26}$ y Clero secular y regular: Inventario de procedencias. $^{27}$ Sin embargo también hay otros de interés relativos sobre todo a códices y sellos. ${ }^{28}$

Además de la Iglesia, la nobleza española ha tenido un enorme protagonismo a nivel político, económico y social en nuestro país. Por ello resulta conveniente conocer, por ejemplo, la procedencia social del medio y alto clero, vinculado al estamento nobiliario, y sobre todo en la Iglesia más importante de la Península Ibérica, como era la Primada de Toledo. Pero también la relación de la nobleza con la erección de iglesias y monasterios y el grave problema para la independencia del clero que supuso el fenómeno conocido como «iglesia propia». Por todo esto, la Sección Nobleza del Archivo Histórico Nacional también es de vital importancia.

\section{Archivo Secreto Vaticano}

En la Constitución Apostólica Pastor Bonus ${ }^{29}$ con efecto desde el 1 de marzo de 1989, promulgada por el Papa Juan Pablo II, en su apartado 187 pone el Archivo Secreto Vaticano y la Biblioteca Apostólica al servicio de los historiadores, incluso para la Historia profana, como fuente de conocimiento universal, ${ }^{30}$ oficializando de esta forma una práctica que ya existía desde el siglo XIX.

El Archivo Secreto Vaticano ha sido sin embargo poco utilizado por la historiografía española para completar sus investigaciones, y en muchos casos sin llegar a establecerse

\footnotetext{
26 Archivo Histórico Nacional. 2000. Catálogo de instrumentos descripción de la Sección de Clero. Madrid. Mecanografiado.

27 Asanza y Núñez Clemente 1924.

28 León Tello y De la Peña 1950-1952; Guglieri Navarro 1974; Inventario de Pergaminos de la Sección de Clero, 10 vols.; Inventario de Libros de la Sección de Clero, 10 vols.

${ }^{29}$ Disponible el texto completo en la página web oficial de la Santa Sede.

30 El artículo 187 exactamente dice: «Entre estas instituciones se distingue el Archivo Secreto Vaticano, en el cual se conservan los documentos relativos al gobierno de la Iglesia, a fin de que estén a disposición en primer lugar de la Santa Sede y de la Curia para realizar su trabajo, y también, por concesión pontificia, puedan ser para todos los historiadores fuentes de conocimiento, incluso de la historia profana, de todas las regiones que en los siglos pasados estuvieron estrechamente ligadas con la vida de la Iglesia».
} 
bien la relación existente entre los temas eclesiásticos hispanos y los generales o los de la política pontificia. Se ha intentado corregir esta falta con los diversos trabajos de la colección Monumenta Hispaniae Vaticana, donde se han publicado colecciones documentales procedentes del Archivo Secreto Vaticano como los Registros, para hacerlos más accesibles a los investigadores españoles.

La historia del mismo y la descripción de sus fondos fue motivo de una de las ponencias a cargo de José Luis González Novalín, Rector de la Iglesia Nacional Española en Roma y de su anexo el Centro Español de Estudios Eclesiásticos, que la Asociación de Archiveros de la Iglesia mantuvo en uno de sus congresos más recientes y que luego se plasmó en sus actas. $^{31}$

El hecho clave para la historiografía mundial fue el proceso de apertura de los mismos al público que se produjo bajo el pontificado de León XIII, concretamente en el año 1881. Este acto favoreció la creación de Institutos Históricos Nacionales para explotar el Archivo con fines investigadores. La presencia investigadora española en Roma se ha hecho notar fundamentalmente a través de dos instituciones situadas en la urbe: la Escuela Española de Historia y Arqueología y el Centro Español de Estudios Eclesiásticos. Este último ha publicado diversas guías de archivos romanos, la ya mencionada Monumenta Hispaniae Vaticana, diversas monografías y la revista "Anthologica Annua».

Para el estudio de la Edad Media el Archivo Secreto Vaticano cuenta con los Registros, una ingente serie documental. Comienzan con las cartas de Juan VIII (872-882) y de Gregorio VII (1073-1085) como los números 1 y 2 de esta larga serie, aunque existen lagunas entre ellos y hasta Inocencio III en el siglo XII cuando se convierten en sistemáticos. Los Registros tienen un significado algo diferente para el lenguaje archivístico vaticano que el que vulgarmente tenemos del mismo. Son una inmensa colección de volúmenes donde se transcribe documentación variada, desde cartas oficiales papales a minutas que no fueron documentos definitivos, todos ellos procedentes de diversas oficinas pontificas.

Para orientar al investigador se han subdividido de la siguiente manera: por un lado, y tras los Registros iniciales sueltos, están los conocidos como Registros Vaticanos, los más importantes, ya que abarcan desde el momento en el que se adopta con carácter sistemático la custodia y registro de la documentación. Estos registros los forman los fondos iniciados con Inocencio III y se cierran al final del siglo XVI con el papa Gregorio XIII. Hay un total de 2020. Se trata principalmente de copias de bulas o de documentación oficial.

Siguen los Registros Aviñonenses, similares a los anteriores pero, como se desprende de su nombre, con la documentación de los papas y antipapas de Aviñón. Es una serie relativamente breve, con 349 volúmenes. De la época del Cisma de Occidente, las cartas de los pontífices reconocidos por Roma pasaron a formar parte de los Registros Vaticanos.

El tercer grupo es el de los Registros Lateranenses, formado por aquellos Registros Vaticanos que fueron llevados a Francia en época napoleónica y luego devueltos a Roma. Su nombre se debe a que, a su vuelta y de forma inicial,

\footnotetext{
31 González Novalín 2007.
}

fueron a San Juan de Letrán en lugar de a El Vaticano. Son 1470 volúmenes con documentación que abarca desde el pontificado de Bonifacio IX (1389) hasta el de León XIII. Su origen parece ser la cancillería pontificia.

Finalmente están los Registros de las Súplicas, con la enorme cantidad de 7400 volúmenes, desde Clemente VI (1342) hasta León XIII. Son peticiones de gracias y privilegios papales realizadas por las más diversas personas.

Los Registros funcionaron, a través del grupo de los Lateranenses, hasta el pontificado de León XIII. Es entonces cuando se pasa la documentación que se iba generando, debido al incremento de su actividad, a los fondos de la Secretaría de Estado con más de 70 subfondos. Obviamente no nos detendremos en describirlos ya que quedan fuera de la época medieval.

La inmensa mayoría de estos Registros se encuentran ya digitalizados y disponibles para el investigador en formato CD-ROM. Pero el alto precio de los mismos y su elevado número ocasionan que la mayoría de las bibliotecas españolas no dispongan de los mismos, o de sólo una parte, a pesar de su enorme utilidad.

El Índice del catálogo del Archivo Secreto Vaticano está ordenado sin un sistema preconcebido; por eso fue siempre preocupación del personal hacerlo de una forma sistemática. Destaca el inventario conocido por el nombre de su promotor, el Schedario Garampi, elaborado gracias a Giuseppe Garampi, sacerdote de Rímini del siglo XVIII, prefecto del Archivo por aquel entonces. Del mismo destaca la serie Vescovi, de 37 volúmenes que contienen bajo el nombre latino de cada diócesis los datos referentes a sus obispos. Se hizo una modernización del mismo en 1989.

\section{Otros archivos}

Obviamente existen otros archivos, sobre todo situados en Toledo, interesantes para el estudio de la Iglesia de Toledo en la Edad Media. ${ }^{32}$ Sin embargo, no son los fundamentales y en muchos casos sólo se podrá sacar de ellos alguna información puntual. Desgraciadamente, como comentó Mariano García Ruipérez en su trabajo sobre los archivos toledanos, no todos están clasificados y ordenados con criterios archivísticos. Además, algunos no disponen de instrumentos descriptivos suficientes.

Una de las instituciones nacionales que no tiene epígrafe propio en este estudio es la Real Academia de Historia. Temporalmente custodió los fondos que hoy en día se encuentran en el Archivo Histórico Nacional, y en la actualidad guarda diversa documentación, alguna de época medieval. Sin embargo, para el caso concreto de nuestro estudio la consulta de sus fondos tiene menos importancia que los de las otras instituciones ya citadas. Entre los manuscritos, de Asensio de Morales destaca la colección de privilegios y escritos de diferentes iglesias de España: son 23 volúmenes con documentos procedentes de diferentes catedrales españolas; aunque no contiene documentación específica de la de Toledo, sí de varias de sus sufragáneas

32 La mayoría de ellos han sido descritos, y no sólo de aquellos con interés para estudios medievales como es nuestro caso, en: García Ruipérez 1997. 
que puede referirse a promesas de obediencia al arzobispo, comunicaciones de elecciones episcopales por los diversos cabildos para ser ratificadas por el toledano,... Además en la Real Academia de Historia se conservan diferentes colecciones de nobleza, casas y familias que pueden ser de utilidad para la elaboración de la prosopografía del clero toledano.

Entre los archivos públicos, el Archivo de la Diputación Provincial de Toledo, con pocos instrumentos descriptivos, contiene en sus fondos medievales los documentos de las instituciones sanitarias y benéfico-asistenciales que, con la revolución liberal burguesa del siglo $\mathrm{XIX}$, pasaron a manos del Estado. María Jesús Cruz Arias estudió los fondos documentales de diversos hospitales toledanos y documentos sueltos de algunas cofradías. ${ }^{33}$

Del Archivo Municipal de Toledo se dispone de la obra de Plácido Ballesteros, María Jesús Cruz Arias y de Mariano García Ruipérez, un trabajo titulado Documentación medieval en los archivos municipales de Castilla-La Mancha ${ }^{34}$ y publicado en el año 1995. En dicho archivo se posee un libro becerro del siglo xv y libros de procedencia municipal, de iglesias y de cofradías. También se conservan diversos privilegios, cartas y cédulas reales que en algunos casos pueden afectar a temas eclesiásticos.

Fuera de la capital manchega, en la cercana Talavera se conservan en el archivo los documentos de la Santa Hermandad de la ciudad, con documentación datada entre 1300 y 1835 . Algunos de los mismos han sido publicados por José María Sánchez Benito en 1990 bajo el título Colección de documentos de la Santa Hermandad. ${ }^{35}$

De utilidad también es el Archivo de Simancas, como primer ensayo logrado de organizar en Castilla un depósito de fondos del estado, y, más concretamente, el Registro General del Sello, donde se incluye numerosa documentación relativa a la segunda mitad del siglo XV.

De los archivos eclesiásticos, el más importante es el ya comentado Archivo Capitular de la Catedral de Toledo. El Archivo Diocesano de la ciudad que, en cierto modo, es su heredero tras la creación del mismo por parte del cardenal Cisneros es menos útil para una investigación medieval, exceptuando el caso de que se realice sobre los años de transición del Medievo al Renacimiento, pues el más antiguo de sus documentos data de 1480 .

Otro de los que puede resultar de interés es el Archivo del Cabildo de Párrocos de Toledo con documentación comprendida entre los siglos XII y XVIII. De este archivo se tiene el Catálogo del Archivo del Cabildo de curas y beneficiados de Toledo, ${ }^{36}$ de Mario Arellano, conservado en la parroquia de San Nicolás.

En Roma, se encuentran los fondos del Centro Español de Estudios Eclesiásticos; la mayoría de los mismos son del siglo XV, de los momentos correspondientes al fin del Cisma de Occidente, y del siglo XVI. ${ }^{37}$

Independientemente de la documentación propiamente archivística, se dispone de diversas fuentes publicadas, sobre todo aquellas que recogen la documentación

\footnotetext{
33 Cruz Arias 2004

34 Ballesteros San José et al. 1995.

35 Sánchez Benito 1999.

36 Arellano García 1984.

37 González Novalín 2007.
}

propia de diversos arzobispos del periodo medieval. Son el Diplomatario del cardenal Gil de Albornoz ${ }^{38}$ dirigida por Emilio Sáez, con 3 tomos publicados que van de los años 1351 a 1359, y la Colección diplomática del cardenal Mendoza (1454-1503) ${ }^{39}$ de Francisco Javier Villalba Ruiz de Toledo.

\section{APÉNDICE: MANUSCRITOS DEL ARCHIVO Y BIBLIOTECA Capitulares de la Catedral de Toledo}

Describimos aquí, en forma de regesta o comentario, algunos de los manuscritos más interesantes para un posible estudio de la Iglesia de Toledo en la Edad Media. Consideramos hacerlo para dicha institución archivística ya que, gracias a la centralización de archivos que existe en España para la Edad Media debida en parte a la existencia del Archivo Histórico Nacional, provoca que los fondos de otros lugares no se conozcan en demasía. Por tanto, esta breve descripción esperamos sirva para dar a entender qué fondos se encuentran en dicho lugar por si pueden resultar útiles para investigaciones futuras sobre el tema.

Sirvan por tanto las siguientes descripciones y regestas no como la totalidad de los fondos, sino una muestra de lo que guardan y los que más tienen que ver con el tema de nuestro artículo, un estudio sobre la Iglesia de Toledo en la Edad Media.

\section{FONDO GENERAL DE PERGAMINOS}

Probablemente el menos conocido y explotado de todos los fondos capitulares toledanos. Mostramos aquí diferentes regestas que pueden dar luz sobre su contenido:

\section{- Regesta de Constituciones Arzobispales, Capitulares y Sinodiales}

Contienen información de cómo se regulaba la vida de los canónigos, en el caso de la capitulares, y del clero de la archidiócesis de Toledo en general, en el caso de las sinodiales.

\section{1.- 1157, mayo; s.l.}

Constitución del arzobispo don Juan con consentimiento del Cabildo de instituir 24 canónigos mayores y 6 menores, sin nombrar ninguno hasta alcanzar dicha cifra.

Signaturas: Z.1.G.1.2; Z.1.G.1.2a; Z.1.G.1.2b

\section{2.- 1174, marzo; s.l.}

Constitución de don Cerebruno, arzobispo de Toledo, por la que establece que el número de canónigos del cabildo de la catedral quede reducido a cuarenta, y prohíbe la admisión de nuevos miembros hasta que esto se consiga. Por la misma, los canónigos serán también los únicos que podrán recibir las rentas asignadas al vestuario capitular.

\footnotetext{
38 AA.VV., Diplomatario del cardenal Gil de Albornoz. Cancillería Pontificia. El primero de los tomos abarca los años 1351 a 1353, el segundo de 1354 a 1356 y el tercero de 1357 a 1359.

39 Villalba Ruiz de Toledo 1999.
} 
Signaturas: Z.1.G.1.3; Z.1.G.1.3a; BCT 42-20 f61r-62r; BCT 42-23 f64v-65r

\section{3.- 1238, julio 10; Toledo}

Constitución de don Rodrigo Jiménez de Rada aumentando el número de racioneros de 30 a 50, con una retribución diaria de dos sueldos, cuyas obligaciones se especifican. El número de canónigos no debe exceder de 40.

Signatura: X.10.A.1.1

\section{4.- 1256, enero 6; Toledo}

Constituciones y estatutos hechos por el deán y el cabildo, con anuencia de don Rodrigo, para la administración de los bienes del Refitor y para el buen funcionamiento de la corporación capitular.

Signaturas: X.10.B.1.1

\section{5.- 1266, marzo 15; Toledo}

Constitución de don Sancho de Aragón, electo de Toledo, y del Cabildo por la que establecen que el canónigo mansionario que reside continuamente o por partes perciba íntegro su vestuario.

Signatura: X.11.C.1.1

\section{6.- 1275, junio 5; Toledo}

Constitución del arzobispo don Sancho y del Cabildo por la que se manda que todo nuevo canónigo de Toledo está obligado a una serie de pagos en dinero o especie antes de percibir ningún rédito de la iglesia.

Signatura: A.12.A.1.5

\section{7.- 1291, mayo 14; Toledo}

Constituciones por el arzobispo de Toledo Gonzalo Pérez Gudiel ordenando las distribuciones que han de percibir los asistentes a las Horas.

Signatura: I.6.B.1.2b; I.6.B.1.2; I.6.C.1.1

\section{8.- 1291, mayo 24; Toledo}

Constitución del arzobispo don Gonzalo Pérez Gudiel con el cabildo determinando la parte de frutos que corresponde percibir a cualquier dignidad de la catedral que falleciere, según la época en que la defunción tuviese lugar.

Signatura: I.6.B.1.2a

\section{9.- 1291, mayo 25; Toledo}

Constitución de don Gonzalo Pérez Gudiel con anuencia del Cabildo, por la que se declara cual es la costumbre válida para estar presente en las fiestas a efecto de residencia y percepción de distribuciones.

Signatura: X.11.C.1.3

\section{0.- 1300, Septiembre 12; Toledo}

El deán y el cabildo aceptan la institución de los abades de Santa Leocadia y San Vicente de la Sierra como dignidades catedralicias. Hecha por Gonzalo Díaz Palomeque con autoridad del papa Bonifacio VIII y determinación de asiento en coro, renta etc.

Signaturas: .I.11.A.1.3; I.11.A.1.5

11.- 1300 , septiembre 27, Toledo

Constitución del arzobispo don Gonzalo Díaz Palomeque prohibiendo que ningún clérigo de la catedral, ni el arzobispo mismo, que tenga algo en tierras de la iglesia, lo pueda transmitir bajo ningún título a persona privilegiada o de fuero especial.

Signaturas: .I.6.B.1.5; .I.6.B.1.5a

12.- 1302, mayo 13, Peñafiel

Constituciones del arzobispo Gonzalo Díaz Palomeque y sus sufragáneos dadas en el concilio de Peñafiel.

Signatura: .V.3.A.1.14.

13.- 1304 , junio 22, Toledo

Constituciones del arzobispo don Gonzalo Díaz Palomeque, mandando el modo como se han de distribuir por tercios los diezmos eclesiásticos del arcedianato de Toledo.

Signatura: .I.9.C.1.2

14.- 1305, Abril 1, Toledo

Constitución de don Gonzalo Díaz Palomeque, arzobispo de Toledo, y del deán y el cabildo, determinando como ley la costumbre antigua de designar un decimario o excusado de cada iglesia parroquial para la obra de la catedral hasta que ésta se termine.

Signatura: . X.3.A.1.7.a.

15.- 1305 , octubre 2, Toledo

El arzobispo don Gonzalo Díaz Palomeque con el deán y cabildo determinan la manera de suplir y dotar los servicios de semana de altar con cargo al suplido

Signatura: .I.6.C.1.4.

16.- 1306, diciembre 31, Toledo

Constitución del Deán y arzobispo y cabildo, mandando cómo han de distribuir lo que corresponde a la misa de tercia entre preste y diáconos, quien la gana y la distribución de las ofrendas en las misas de seis capas.

Signatura: .I.6.C.1.2.

17.- 1307 , octubre 23, Toledo

Constitución de don Gonzalo Díaz Palomeque, arzobispo de Toledo, y del cabildo por la que confirma otra anterior de don Sancho, arzobispo de Toledo, sobre la residencia suficiente para ganar los frutos de los préstamos, ampliando el sentido de la constitución anterior.

Signatura: .X.11.C.1.2.

18.- 1330 , junio 27, Toledo

Constitución del arzobispo Jimeno de Luna, el deán y el cabildo mandando que los beneficiados de la catedral, aunque sean presbíteros, tengan obligación de hacer semana de evangelio como los diáconos.

Signatura: I.6.B.1.11.

19.- 1330 , junio 27 , Toledo

Don Jimeno, arzobispo de Toledo, de acuerdo con el deán y cabildo, manda que siendo ya cuarenta los que tienen voz en el cabildo y por los inconvenientes que ello da, no se conceda a ninguno más ni voz ni fruto aunque tengan expectativas de beneficios.

Signatura: A.12.A.1.4; A.12.A.1.4a. 
20.- 1330, junio 27, Toledo

Jimeno de Luna, arzobispo de Toledo, manda que los capellanes de Coro de la catedral no puedan aceptar beneficios servideros en las parroquias de la ciudad, porque ello va en perjuicio de su asistencia.

Signatura: E.1.A.3.5.

\section{1.- 1331, junio 6, Alcalá de Henares}

El arzobispo don Jimeno de Luna, de acuerdo con el cabildo prorroga el plazo para que los capellanes de la catedral puedan renunciar otros beneficios o permutarlos con capellanías fuera de la ciudad quedándose con uno sólo.

Signatura: I.6.B.1.12.

\section{2.- 1336, agosto 2, Alcalá de Henares}

Constitución del arzobispo don Jimeno de Luna sobre la fecha de la celebración del sínodo anual, sobre distribución de frutos a la muerte del beneficiado y reducción de fiestas de precepto.

Signatura: I.12.B.1.1.

28.- 1339, diciembre 29, Toledo.

Constituciones del arzobispo don Gil de Albornoz sobre la celebración de aniversarios en la catedral, el paso de un coro a otro sin necesidad, celebración de la misa...

Signatura: I.6.B.1.6.

29.- 1342, abril 16, Toledo

Constituciones del arzobispo don Gil de Albornoz privando de sepultura eclesiástica a las públicas concubinas de los clérigos y ordenando los diezmos de los frutos de ganados

Signatura: I.6.B.1.4.

\section{0.- 1342, abril 26, Toledo}

Constituciones del arzobispo don Gil de albornoz asignando dotaciones a ciertas fiestas y distribuciones.

Signatura: I.5.C.1.7.

\section{1.- 1342, abril 26, Toledo}

Constitución del arzobispo don Gil de Albornoz, disponiendo el modo de celebrar en el altar mayor de la catedral, las personas que han de hacerlo y prohibiendo alguna corruptela introduciendo la celebración en altar de madera y en las gradas del altar.

Signatura: I.6.B.1.8.

\section{2.- 1345, abril 11, Alcalá de Henares}

Copia de unas constituciones del arzobispo don Gil de Albornoz, en sínodo de Alcalá, mandando se guarden las costumbres de que al fallecimiento de cualquier clérigo del arzobispado se den al arzobispo de sus bienes una cosa preciosa, y que cada año paguen el tributo llamado catedrático.

Signatura: I.6.A.1.1.

33.- 1345, mayo 13, Alcalá de Henares

Don Gil de Albornoz, arzobispo de Toledo expide una carta, por la que dispensa de una constitución recientemente aprobada en el sínodo de Alcalá a los beneficiados de la iglesia de Toledo, mandando que las cosas queden en el estado anterior.

Signatura: V.1.F.1.36
34.- 1346, mayo 16, Toledo

Constitución en que el arzobispo don Gil de Albornoz determina la manera de hacerse las distribuciones entre los asistentes al coro, las penas que han de sufrir y algunos particulares sobre ello.

Signatura: I.6.B.1.10.

35.- 1349 , febrero 15, Toledo

Constituciones del arzobispo don Gil e Albornoz, ordenando el cumplimiento de cargar de las capellanías en la catedral, condiciones de los capellanes, en ausencia qué pueden disfrutar, etc.

Signatura: I.6.B.1.9.

36.- 1351, Junio 24, Alcalá de Henares

Constituciones del arzobispo don Gonzalo de Aguilar sobre beneficios y prebendas, sus frutos y residencia.

Signatura: I.6.B.1.15.

37.- 1354, mayo 9, Alcalá de Henares

Constituciones del arzobispo don Blas Fernández de Toledo, en sínodo celebrado en Alcalá, en las que prohíbe a los clérigos la administración de bienes de seglares, determina la obligación de las constituciones, cambia la fecha anual del sínodo y determina la cuantía del tributo llamado catedrático.

Signatura: I.6.B.1.3.

38.- 1356, mayo 3, Toledo

Constituciones sinodales mandadas publicar por el arzobispo don Blas Fernández de Toledo, comprensivas de parte dogmática, moral y disciplinar.

Signatura: I.6.A.1.2.

39.- 1356, Julio 5, Toledo

Don Blas, arzobispo de Toledo, da unas constituciones para que el deán al ausentarse nombre vicedeán, y si no lo nombra, lo haga el cabildo.

Signatura: I.6.B.1.13.

40.- s. XIV

Constitución en los que el deán y cabildo resuelven cómo se ha de distribuir las ofrendas que se hagan en la misa de la catedral, por reyes, infantes, ricos hombres,... según que leguen o pasen de 30 maravedíes.

Signatura: I.6.C.1.3.

41.- 1437, febrero 26; Roma

Carta del arzobispo Juan de Cerezuela en la que ordena al deán y cabildo que den las capellanías de los clérigos ausentes a clérigos de misa idóneos y suficientes.

Signatura: E.1.A.3.8a.

42.- 1447, junio 20; Alcalá de Henares

El arzobispo Alonso Carrillo concede a todos los canónigos, racioneros, capellanes y semaneros de la catedral que tengan algún beneficio en iglesias parroquiales de la ciudad que no sean obligados en adelante a prestar el tributo llamado luctuosa.

Signatura: 0.2.V.1.2. 
43.- 1456, octubre 17; Alcalá de Henares

Concordia de Alfonso Carrillo con el cabildo en la que se reparten la provisión en los seis meses ordinarios.

Signatura: Z.1.G.1.8.

44.- 1462, julio 27; Toledo

Constitución de Alfonso Carrillo con consentimiento del cabildo en la que ordena que los dos oficios de vicario y capellán mayor sean considerados dignidades.

Signatura: I.9.A.1.10.

\section{5.- 1468, enero 24; Arévalo}

Constitución dada por Alfonso Carrillo en la que confirma un estatuto dado por el cabildo el 4 de enero de ese año a cerca de la situación de los canónigos pensionarios.

Signatura: I.6.C.1.5.

46.- 1476, abril 27; Roma

Bula de Sixto IV instituyendo dos canonjías de oficio, doctoral y magistral, para personas versadas en Derecho y Teología.

Signatura: A.12.1.2.4

\section{7.- s. XV}

Constitución en la que se determina que todos los años el primero de enero se nombren dos mayordomos que administren lo temporal del Cabildo prestando juramento y con determinación de retribuciones y deberes.

Signatura: I.6.C.1.9

\section{- Actas Capitulares}

En las mismas se iba consignando, en las diferentes reuniones del Cabildo de la Catedral de Toledo, las decisiones que había tomado en temas diversos (compra-ventas de propiedades, disposiciones sobre fiestas, asignaciones de gastos, ordenamientos sobre formas de actuación de los capitulares, tomas de posesión, vacantes, pleitos...).

Aunque prácticamente cubren toda la Edad Moderna, de época medieval se conservan tres tomos, siendo su signatura en el Archivo el número que la precede:

0. Actas Capitulares 1351-1352: Llevan el número 0 al haberse localizado en el Archivo tiempo después de la catalogación de la serie que comienza en 1466. Es interesante además por incluir una relación del pago de diezmos de cada uno de los lugares del arzobispado de Toledo en esta época.

1. Actas Capitulares 1466-1490

2. Actas Capitulares 1490-1501

\section{- Regesta de privilegios reales}

Como la diócesis más importante del ámbito de la Corona castellano-leonesa, el arzobispado de Toledo recibió muchos e importantes privilegios por parte de diversos monarcas a lo largo de la Edad Media, de cuyos originales o copias autenticadas se hallan en el Archivo.

Entre los más importantes se encuentran el derecho a la exención de posada a los oficiales reales por parte de los capitulares toledanos o la inmunidad judicial eclesiástica, que obligaba que todo clérigo sólo pudiera ser juzgado por parte de jueces de la Iglesia.
Para su relación aconsejamos acudir a la ya citada obra de García Luján ${ }^{40}$ donde, además de transcribirlos, contiene dicha relación con 120 documentos.

\section{- Regesta de inventarios}

A partir del siglo XIV sobre todo, aunque algunos de época anterior, aparecen una serie de inventarios ${ }^{41}$ de diverso contenido: ajuar litúrgico, libros, joyas, ornamentos,... siendo en muchos casos la relación de los mismos que un arzobispo recibía de su antecesor al ser elegido.

1.- s. XIII (ca. 1257)

Inventario del Sagrario de don Rodrigo Yuanes, tesorero, contenido en el códice Liber Priuilegiorum Toletanae ecclesiae.

Signatura: BCT 42-23a, fols. 76-77

2.- 1277 , abril 1. Toledo

Inventario del Sagrario dado por el Cabildo a don Sancho Martínez, tesorero con datos del ajuar litúrgico y libros

Signatura: X.12.B.1.1

3.- 1273, mayo 3. Alvaladiel

Dos inventarios de los bienes de don Gonzalo Pérez al ser nombrado obispo de Cuenca.

Signatura: A.7.H.1.1; A.7.H.1.1 ${ }^{\mathrm{a}}$

4.- 1280 , diciembre 6. Viterbo

Inventario de los bienes de la casa de Gonzalo Pérez, electo arzobispo de Toledo, cuando residía con la curia papal antes de ser trasladado a Toledo.

Signatura: A.7.G.1.12

5.- 1281, noviembre 6. S.I.

Inventario-concordia de don Gonzalo Pérez con fray Fernando, obispo de Burgos, su antecesor, que recoge los objetos y libros que don Gonzalo debía devolver al obispo de Burgos.

Signatura: A.7.G.1.4

6.- 1282, septiembre 5. Aviñón

Inventario de las joyas y libros de sus antecesores recuperados por don Gonzalo Pérez, arzobispo de Toledo, en Aviñón, y que estaban depositados como garantía de las deudas en la banca de los Marsupino de Pistoia.

Signatura: A.7.G.2.18

7.- 1320, marzo 7. S.I.

Inventario de las alhajas, joyas y libros rescatados por el arzobispo don Juan de Aragón por medio del deán don Vasco Fernández de Toledo de las cosas que sus antecesores depositadas y empeñadas en Montpellier.

Signatura: A.8.C.1.6

8.- 1328, noviembre 14. Toledo

Inventario por el cual el deán y cabildo de Toledo reconocen que han tomado del Sagrario, donde está el Tesoro de

40 García Luján 1982.

41 La siguiente relación está basada en un documento impreso del Archivo Capitular de la Catedral de Toledo y el catálogo de fichas, disponibles ambos para los investigadores. 
la Iglesia, diversos objetos de plata, a saber, un cáliz grande que dio Sancho IV, más otros tres cálices, siete lámparas de plata que dio el arzobispo Gutierre Gómez de Toledo además de otra plata de un crucifijo con el fin de financiar el pleito por la villa de Illescas y el compromiso de devolver o pagar su precio.

Signatura: X.12.B.1.15a

\section{9.- 1339 , febrero 17 . Toledo}

Inventario del Sagrario contenido en una escritura notarial por la cual Gonzalo González, canónigo y veedor de la Obra certifica la recepción de diversos objetos de plata de Gonzalo Ruiz, tesorero del cabildo de la catedral de Toledo, en calidad de préstamo para la Obra, con la condición de que los devolverá el próximo día de Pascua mayor.

Signatura: X.12.B.1.1a; X.12.B.1.15

10.- 1339, junio 3. La Guardia

Inventario contenido en una escritura notarial por la cual don Gil Álvarez de Albornoz, arzobispo de Toledo, reconoce haber recibido de don Gonzalo Ruiz, tesorero de Toledo, por medio de Fernando Sánchez, su camarero, una serie de objetos litúrgicos y libros del Sagrario para su uso personal, destinados a la capilla arzobispal.

Signatura: X.12.B.1.18

11.- ca. 1343

Inventario de las piezas del Sagrario, que fueron entregadas a Bernalt Safont, tesorero, y aquellas otras que no le fueron entregadas por estar en poder de don Gil, arzobispo de Toledo.

Signatura: X.12.B.1.2

\section{2.- ca. 1343}

Inventario de las piezas del Sagrario custodiadas por Bernalt Safont, tesorero, especificadas por materias.

Signatura: X.12.B.1.2 ${ }^{\mathrm{a}}$

\section{3.- 1343 , enero 17. Toledo}

Inventario de los ornamentos y libros litúrgicos que recibió Miguel García, representante de Bernalt Safont, tesorero.

Signatura: X.12.B.1.6 (supl. 122)

\section{4.- 1343 , noviembre 15. La Guardia}

Inventario contenido en una escritura notarial por la cual don Gil Álvarez de Toledo, arzobispo de Toledo, reconoce haber recibido de don Gonzalo Ruiz, tesorero de Toledo, por medio de Domingo Yagüe, su clérigo, una serie de objetos litúrgicos y libros del Sagrario para su uso personal, destinados a la capilla arzobispal.

Signatura: X.12.B.1.17

\section{5.- 1351, junio 6. Alcalá de Henares}

Inventario contenido en una escritura notarial por la cual don Gonzalo de Aguilar, arzobispo de Toledo, reconoce haber recibido del Sagrario de la Catedral de Toledo, que está a cargo de Bernalt Safont, tesorero, una serie de objetos, ornamentos y libros para uso de su capilla.

Signatura: X.12.B.1.16
16.- 1354, octubre 8, Alcalá de Henares

Inventario de los objetos que don Vasco Fernández de Toledo, arzobispo de Toledo, y en su nombre don Bernalt Safont, tesorero, su clérigo, recibió para su uso y su capilla, del Sagrario de la iglesia de Toledo, en el que figuran ornamentos, libros y objetos litúrgicos

Signatura: X.12.B.1.10; X.12.B.1.9

17.- 1361, octubre 7. Toledo

Inventario recogido en el acta del Cabildo de la catedral de Toledo por la cual reconoce que por las especiales dificultades económicas en que se halla, motivadas por la necesidad de pagar las procuraciones del cardenal-legado Guido, y las caballerías, diezmos y pechos que quiere tomar del cabildo el rey Pedro I, se ha visto obligado a tomar del Sagrario varios objetos tasados en 25.310 maravedíes, los cuales se compromete a devolver o a pagar su precio.

Signatura: X.12.B.1.14

\section{8.- 1363, enero 3. Toledo}

Inventario del ajuar litúrgico, libros y objetos del Sagrario de la Catedral de Toledo que don Gome Manrique, electo confirmado arzobispo de Toledo, recibió de don Bernalt Safont, tesorero, electo confirmado obispo de Cuenca, para su uso personal y de su capilla.

Signatura: X.12.B.1.13

19.- 1400 , abril 6. Toledo

Inventario de objetos del Sagrario realizado por mandato de don Diego Fernández Gudiel, deán de la Catedral de Toledo

Signatura: X.12.B.1.3 (Supl. 143)

\section{0.- ca. 1430}

Fragmento de un inventario del Sagrario de la catedral de Toledo de ornamentos, textiles, orfebrería litúrgica y reliquias

Signatura: X.12.B.1.17a

\section{1.- 1455, enero 29. Toledo}

Inventario de los libros de la iglesia de Toledo, por Pedro Rodríguez de Durazno, canónigo y Rodrigo Fernández, bachiller en leyes y Alfonso López de Coca, notario.

Signatura: BCT 41-43

\section{- Regesta sobre la primacía de Toledo}

En su triple vertiente (obispo de una diócesis, metropolitano de una provincia eclesiástica y primado de España), por la última de ellas, la de primado, muchos fueron los documentos que, sobre todo provenientes de la cancillería pontificia, fueron custodiados en el Archivo.

Este gran volumen tiene en parte su origen en las distintas disputas sobre dicho derecho otorgado por los papas de Roma basándose en la antigua primacía de la iglesia toledana de época visigótica.

Cuando en el IV Concilio de Letrán se vuelve a reafirmar la Primacía en el arzobispo de Toledo, aunque de una forma prácticamente honorífica, dichas confirmaciones por parte de Roma prácticamente desaparecen, excepto algún caso bajo el pontificado de Martín V, siendo sustituidas por 
ciertos pleitos que se interponen cuando, utilizando esta prerrogativa honorífica, el prelado de Toledo intentaba pasar por alguna diócesis ajena a la suya o a sus sufragáneas con la cruz levantada, en señal de Primacía, que los obispos de otras diócesis impedían por ser un derecho reservado a sus metropolitanos.

\section{1.- 1086 , diciembre 18. Toledo}

Privilegio de Alfonso VI restaurando la sede arzobispal, entregando las antiguas mezquitas para que sean iglesias, concediendo donaciones en Toledo, Talamanca, Guadalajara,... y sometiendo a la jurisdicción del arzobispo de Toledo los monasterios, obispos, abades y clérigos de su imperio. Se elige arzobispo a don Bernardo de Sahagún.

Signaturas: O.2.N.1.1; 0.2.N.1.2; O.2.N.1.3; I.7.I.1.11

\section{2.- $1088-1169$}

Copias de 8 bulas sobre la primacía

Signatura: X.7.A.5.1b

\section{3.- 1088 , octubre 15. Anagni}

Urbano II, bula Cunctis sanctorum al arzobispo de Toledo don Bernardo, confirmando su elección, concediéndole el palio y designándole Primado.

Signatura: X.7.A.1.1

\section{4.- 1101, marzo 6. Letrán}

Pascual II, bula Actorum synodalium confirmando la primacía

Signatura: X.7.A.1.3

\section{5.- 1118, noviembre 7. San Egidio}

Privilegio Caritatis est bonum de Gelasio II confirmando la Primacía y exhortando a cumplir rectamente su ministerio al arzobispo

Signatura: X.7.A.1.4

\section{6.- 1122, noviembre 3. Matera}

Calixto II, bula Postquam superne II confirmando los privilegios de Urbano II y Pascual II sobre la primacía al arzobispo don Bernardo.

Signatura: X.7.A.1.5; X.7.A.1.6

\section{7.- 1125 , noviembre 30. Letrán}

Honorio II, bula Sacrosancta romana reafirmando la primacía y el derecho de palio, así como la jurisdicción sobre las diócesis de Oviedo, León, Palencia y las aún sometidas por los musulmanes.

Signatura: X.7.A.1.7b

\section{8.- 1138-1142, abril 24. Letrán}

Inocencio II, bula Apostolicae Sedis dirigidas a los arzobispos y obispos de España, en las cuales confirma a don Raimundo de Toledo el privilegio de primacía y les manda que le presten obediencia y reverencia.

Signatura: X.7.A.1.8

9.- 1144, mayo 13. Letrán

Lucio II, bula Sacrosancta romana reconociendo la primacía

Signatura: X.7.A.1.9a
10.- 1148, abril 16. Reims

Letras apostólicas de Eugenio III Aposttolice sedis clementia dirigidas a los prelados de España que confirman la primacía después de que don Raimundo haya ido a verle con los privilegios de la misma, y les manda que le obedezcan y reverencien como primado.

Signatura: X.7.A.1.10

10.- 1149, diciembre 9. Letrán

Letras apostólicas de Eugenio III Sicut ex inspectione dirigidas a Alfonso VII dándole cuenta de cómo ha dotado a la iglesia de Compostela con la prerrogativa de portar la cruz delante de su metropolitano y de las diversas incidencias ocurridas con motivo de la negativa del arzobispo de Braga a rechazar la obediencia al de Toledo como primado.

Signatura: X.7.A.2.2

11.- 1150, mayo 17. Toledo

Noticia de cómo en ese día don Juan, arzobispo de Braga, prestó obediencia canónica a don Raimundo de Toledo como primado.

Signaturas: BCT 42-21 f57r; BCT 42-22 f37r

12.- 1152,13 de febrero. Roma

Eugenio III, bula Potestatem ligandi confirmando la primacía tras la visita que ha recibido del arzobispo Juan, a los arzobispos y obispos de España, exigiéndoles la obediencia debida al mismo.

Signatura: X.7.A.2.1a

\section{3.- 1156, 9 de febrero. Benevento}

Adriano IV, bula Cum pro negotiis dirigidas a don Juan de Toledo en que se confirma el privilegio de primacía sobre todos los obispos y arzobispos de España, y declara que el privilegio que obtuvo don Pelayo, arzobispo de Compostela, de su predecesor Anastasio IV para no estar sujeto al de Toledo, queda invalidado en el futuro.

Signatura: X.7.A.2.4

14.- 1155, marzo 3. Nájera

Letras Offici nostri debitum del cardenal Jacinto, legado de la Sede Apostólica a Juan de Toledo comunicándole que, puesto que el arzobispo de Braga no le ha prestado obediencia como Primado ni ha comparecido en el Concilio de Valladolid, como contumaz y rebelde, lo ha suspendido de oficio pontifical y ha absuelto a los sufragáneos de la obediencia, hasta tanto que cumpla los mandatos pontificios.

Signatura: X.8.C.1.1a

15.- 1161, 25 de febrero. Anagni

Alejandro III, bula Quante dignitatis dirigido a don Juan de Toledo, confirmándole la primacía, la posesión de la parroquia de Alcalá, la jurisdicción metropolitana sobre Osma, Sigüenza, Segovia y Palencia y la posesión y uso del palio arzobispal.

Signatura: X.7.A.2.6

16.- 1163, 10 de julio. Dôle

Alejandro III, bula Cum pro celebratione dirigida a Juan de Toledo, en el que le confirma la primacía, incluso sobre 
Braga y Compostela, y concediéndole licencia para proseguir la causa contra el de Tarragona.

Signatura: X.7.A.2.8

17.- 1166, 11 de diciembre. Letrán

Alejandro III, bula Sacrosancta romana dirigida a don Juan, arzobispo de Toledo, en que se confirma la primacía, regula el uso del palio, le confirma la posesión de la diócesis de Alcalá, le señala las sufragáneas y le da derecho de someter aquellas diócesis que vayan siendo libradas de los sarracenos, hasta que se conquisten sus propias metrópolis.

Signatura: X.7.A.2.9

\section{8.- 1167-1180, mayo 15. Letrán}

Letras apostólicas Quod a predecessoribus de Alejandro III dirigidas a los obispos de Oviedo, León y Burgos, mandándoles que en término de dos meses desde la recepción de la bula presten la debida reverencia y sujeción a don Cerebruno, arzobispo de Toledo, como primado.

Signatura: X.7.A.2.10

\section{9.- 1169 , noviembre 24. Benevento}

Alejandro III, bula Cum pro negotiis a don Cerebruno reconociéndole la Primacía y anula el privilegio de exención concedido por el papa Anastasio IV a don Pelayo, arzobispo de Compostela.

Signatura: X.7.A.2.11a; X.7.A.2.11b

\section{0.- 1176, febrero 26. Anagni}

Letras apostólicas de Alejandro III Cum a patribus dirigidas al arzobispo de Braga y a sus sufragáneos, mandándoles que en término de dos meses desde la recepción de esta bula presten obediencia a don Cerebruno, arzobispo de Toledo, como a primado, y les da cuenta de cómo ha mandado al obispo de Zamora que le retire la obediencia como metropolitano, mientras el de Braga no obedezca como primado al de Toledo.

Signatura: X.8.A.1.2

\section{1.- 1176, febrero 27. Anagni}

Letras apostólicas de Alejandro III Sicut predecesores nostri dirigidas al obispo de Zamora, mandándole que no obedezca al arzobispo de Braga como a metropolitano, hasta que el mismo no acate como primado al toledano, bajo pena de quitarle la facultad de consagrar iglesias y altares y de aumentarlas en el próximo concilio general que se va a celebrar.

Signatura: X.8.A.1.1

\section{2.- 1187, mayo 6. Verona}

Urbano III, bula Sacrosancta romana dirigida a Gonzalo Pérez, arzobispo de Toledo, en que confirma la primacía, señala los límites y toma bajo su protección las ciudades, posesiones y derechos de la iglesia de Toledo, como le habían hecho sus predecesores.

Signatura: X.7.A.2.12a

23.- 1192, junio 6. Roma

Celestino III, bula Sacrosancta romana dirigida a don Martín López de Pisuerga en que le confirma el privilegio de la primacía, señala las ciudades y fortalezas del arzobispado, sus posesiones y derechos.

Signatura: X.7.A.2.13a; I.7.I.1.11; X.7.A.2.13b

24.- 1210, marzo 4. Letrán

Inocencio III, constitución solemne Sacrosancta romana a favor de Toledo (primacía) y señala sus diócesis de la provincia y especifica las posesiones de la Iglesia toledana.

Signatura: X.7.A.3.1

25.- 1214, diciembre 2. Letrán

Letras apostólicas de Inocencio III «Venerabilis frater noster» dirigidas a don Rodrigo Jiménez de Rada comunicándole que ha decidido no seguir el consejo del obispo de Segovia, que por parte del de Toledo rogaba al papa que citase al arzobispo de Braga para responder en la cuestión de la primacía, sino que es mejor que venga al concilio general, para que no deje de venir por excusas.

Signatura: X.B.A.1.3

\section{6.- 1216, enero 12. Letrán}

Letras apostólicas de Inocencio III Liter inter venerabilem dirigidas al arzobispo y Cabildo de Braga, comunicándoles que, originada una lite entre Cerebruno (sic) y el de Braga, les asigna como término perentorio la próxima fiesta de Todos los Santos, para que envíen sus procuradores, a fin de que sea debidamente solucionado en derecho la cuestión de la primacía.

Signaturas: X.8.A.1.4; X.8.A.1.4a

\section{7.- 1216, enero 22. Letrán}

Letras apostólicas de Inocencio III Presentium vobis auctoritate dirigidas a los abades y priores de Matallana y de Espina en la diócesis de Palencia, en que les manda que intimen unas letras apostólicas del papa sobre la cuestión de la primacía al arzobispo y al cabildo de Braga para que cumplan su contenido y envíen una relación escrita al Papa.

Signaturas: X.8.A.1.5; X.8.A.1.7 (con fecha de 16 de Agosto)

28.- 1216, noviembre 22. Letrán

Letras apostólicas de Honorio III Te ac Johanne dirigidas a don Rodrigo Jiménez de Rada manifestando que ha recusado aceptar la prorrogación del término para aducir testigos postulada por Johannes, clérigo de Braga, procurador de Esteban Soares da Silva, arzobispo de Braga, por haberse comportado correctamente J. Gutierrii, canónigo de Toledo, en la presentación y atención de los testigos y no así el arzobispo de Braga, de todo lo cual da testimonio el Papa.

Signatura: X.8.A.1.6

\section{9.- 1217, febrero 20. Letrán}

Letras apostólicas de Honorio III Coram felicis memorie dirigidas al arzobispo y al cabildo de Braga, concediéndoles a petición de sus representantes, el maestreescuela y el maestro D., canónigo de Braga, una nueva prórroga hasta la octava de Pentecostés próxima, a fin de que puedan aducir testigos en la causa que se instruye entre los arzobispos de Toledo y de Braga sobre la primacía.

Signatura: X.8.A.1.8 


\section{0.- 1218, enero 2. Letrán}

Letras apostólicas de Honorio III Supplicasti nobis frater dadas a petición de don Rodrigo Jiménez de Rada, dando copia de tres letras apostólicas de sus predecesores, tomándolas de los registros pontificios.

Signatura: X.7.A.3.4a

\section{1.- 1218, enero 5. Letrán}

Letras apostólicas de Honorio III Suplicasti nobis frater dirigidas a don Rodrigo Jiménez de Rada que a petición suya les da cuatro copias de privilegios apostólicos tal y como existen en los registros pontificios.

Signatura: X.7.A.3.4b

\section{2.- 1218, enero 7. Letrán}

Letras apostólicas de Honorio III dirigidas a don Rodrigo Jiménez de Rada transcribiéndole los registros pontificios con nueve bulas relativas a la primacía.

Signatura: X.7.A.3.4c

\section{3.- 1218, enero 8. Letrán}

Letras apostólicas de Honorio III «Suplicasti nobis frater» dirigidas a don Rodrigo Jiménez de Rada, transcribiéndole copias de bulas de Urbano II, carta de Alfonso VI y del legado papal, tomadas de sus registros (siete documentos en total).

Signatura: X.7.A.3.4d

\section{4.- 1218, 19 de enero. Letrán}

Honorio III, bula Cum tu frater dirigidas a don Rodrigo Jiménez de Rada en que se le comunica que, ponderadas las circunstancias de las cosas y de los tiempos, ha decidido no proceder por el momento a dictar una sentencia definitiva en la causa que se ventila sobre la primacía entre los arzobispos de Toledo y Braga, quedando las actas cerradas bajo bula pontificia y otras entregadas a las partes correspondientes.

Signatura: X.8.A.1.9

\section{5.- 1218, enero 25. Letrán}

Honorio III, constitución solemne Apostolicae sedis dirigido a Rodrigo Jiménez de Rada por la que le extiende el derecho de la primacía sobre la metrópoli de Sevilla y su provincia, cuando sea conquistada a los moros

Signatura: X.7.A.3.2a

\section{6.- 1231, mayo 22. Letrán}

Constitución apostólica de Gregorio IX Apostolice sedis benignitas dirigidas a don Rodrigo Jiménez de Rada, arzobispo de Toledo y a sus sucesores, por la que le confirma el privilegio de Honorio III y extiende el derecho de primacía de Toledo sobre la metrópoli de Sevilla y su provincia cuando se conquiste a los moros.

Signatura: X.7.A.3.5a

\section{7.- 1232, abril 4. Letrán}

Letras apostólicas de Gregorio IX Cum venerabilis frater, dirigidas a todos los reyes y príncipes de España, comunicándoles que como quiera que el arzobispo de Toledo tenga derecho a la primacía en Sevilla y su provincia, les manda que le permitan el ejercicio de dicho derecho en cualquier lugar de dicha provincia que sea conquistada a los moros.

Signatura: X.7.A.3.6

\section{8.- 1234, mayo 6. Letrán}

Letras apostólicas Cum super causa de Gregorio IX a los obispos de Segovia, Salamanca y al maestro Arnaldo, electo de León, mandándoles que en la causa que se ve en presencia del Papa sobre la primacía entre el arzobispo y Cabildo de Toledo y el arzobispo y Cabildo de Compostela, concedan a ambas partes el término de un año desde la próxima fiesta de Todos los Santos, para que aduzcan testigos y documentos y que dichos obispos instruyan la causa y la envíen a Roma, dándoles un término perentorio de cuatro meses para que se presenten.

Signatura: X.8.C.1.1

\section{9.- 1236, mayo 7. Viterbo}

Letras apostólicas Cum super causam de Gregorio IX, dirigidas a los obispos de Burgos, Segovia y Salamanca mandándoles que, no obstante las letras anteriores dirigidas a los obispos de Segovia, Salamanca y al difunto de León, continúen en el negocio que se litiga sobre la primacía entre el arzobispo de Toledo y el de Compostela, fijen a las partes un término de un año a partir de la próxima Navidad, instruyan la causa y la envíen a Roma, y se presenten después al Papa.

Signatura: X.8.C.1.2

40.- 1237, septiembre 19. Benavente

Parte del proceso canónico del litigio sobre la primacía entre la iglesia de Toledo y la de Compostela, actuando por orden de Roma, por los obispos de Salamanca y Segovia, que incluyen documentos y bulas pontificias.

Signatura: X.8.C.1.3

41.- 1240, mayo 26. Letrán

Letras apostólicas de Gregorio IX Suplicasti nobis frater dirgidas al arzobispo de Toledo y al Cabildo, en las que el papa da cuenta de que en los registros apostólicos de Urbano II se encuentran varios documentos (siete en total) relacionados con la primacía de Toledo.

Signatura: X.7.A.3.7a

42.- 1240, junio 1. Letrán

Letras apostólicas de Gregorio IX Supplicasti nobis frater dirigidas a don Rodrigo Jiménez de Rada y al Cabildo en que el papa, a instancia del Arzobispo, atestigua que en los registros pontificios de sus predecesores Adriano IV, Anastasio IV y Alejandro III se contienen varios documentos (siete en total) que afectan a la primacía de Toledo.

Signatura: X.7.A.3.7c

\section{3.- 1241, abril 16. Letrán}

Letras apostólicas de Gregorio IX Venerabili fratri nostro dirigidas a Pedro de Albalat, arzobispo de Tarragona, dándole a conocer que con el consentimiento de los cardenales, el papa da por cancelada la excomunión decretada por el de Tarragona en un concilio de Valencia contra el Arzobispo de Toledo, por llevar la cruz alzada por la provincia de Tarragona.

Signaturas: X.7.A.3.8; X.8.H.1.1

44.- 1290 , julio 15. Valladolid

Documento notarial por el que Gonzalo Pérez Gudiel, arzobispo de Toledo, temiendo que don Tello, arzobispo de Braga, 
se atreva a pasar por su provincia con la cruz alzada en detrimento de derecho de la primacía, publica unas sentencias de excomunión y entredicho y manda a los obispos, especialmente al de Palencia y a los demás prelados y rectores de las iglesias, que guarden estas sentencias, en caso de que dicho arzobispo se atreva a pasar por sus lugares en la dicha forma.

Signatura: X.8.A.1.11

\section{5.- 1290, julio 18. Valladolid}

Poder dado por Gonzalo Pérez Gudiel, arzobispo de Toledo, al maestro Jofré de Loaysa, arcediano de Toledo, y a Miguel Jordán, arcediano de Segorbe, para publicar en presencia de don Tello, arzobispo de Braga, unas sentencias de excomunión y entredicho contra los que se atrevan a llevar la cruz alzada por Toledo y su provincia eclesiástica.

Signatura: X.8.A.1.10

\section{6.-1292, mayo 19. Valladolid}

Testimonio notarial de la apelación interpuesta ante la Santa Sede por don Gonzalo Pérez Gudiel, arzobispo de Toledo, por temor que el obispo de Calahorra o su vicario le impidan pasar por su territorio con la cruz de primado alzada como acostumbra.

Signatura: X.8.E.1.1

\section{7.- 1292, junio 2. Soria}

Testimonio notarial de cómo don Gonzalo Pérez Gudiel, arzobispo de Toledo, intimó al obispo de Pamplona cierta sentencia de penas canónicas, para que no perturbara su derecho a pasar por su territorio con la cruz alzada como primado.

Signatura: X.8.E.1.1

\section{8.- 1293, febrero 26. Fuentes del Duero}

Acta notarial de cómo el maestro Jofré de Loaysa, arcediano de Toledo, Nuño Díaz, arcediano de Alcaraz, el maestre Esteban Alfonso, doctor en leyes, y Fernán Guillem, canónigos de Toledo, procuradores de don Gonzalo Pérez Gudiel, arzobispo de Toledo, pretendieron leer ante don Rodrigo González de León, arzobispo de Compostela, dos letras, una de procuración y otra de excomunión por las que se lanzaba entredicho contra el arzobispo de Compostela por haber ido con la cruz alzada por Segovia y Palencia, y de cómo les fue impedido violentamente leer dichas letras por el de Compostela y sus criados.

Signatura: X.8.C.1.4

\section{9.- 1293, agosto 21. Logroño}

Testimonio notarial de cómo habiendo don Almoravid, obispo de Calahorra, lanzado entredicho contra la villa de Logroño por haber entrado en ella con la cruz alzada de primado don Gonzalo Pérez Gudiel el 22 de julio, temiendo ser objeto de penas eclesiásticas por parte de dicho obispo y por haber amonestado a don García Gutiérrez, arzobispo de Sevilla a que no pasara con su cruz alzada por dicho lugar, como lo hizo el 3 de Agosto, apela a la Santa Sede.

Signatura: X.8.E.1.2

\section{0.- 1302, julio 1. Roa}

Testimonio notarial de cómo don Gonzalo Díaz Palomeque, arzobispo de Toledo, dijo que él era primado en todas las Españas y por ello, le correspondía el derecho de entrar con cruz alzada en todos los lugares, pero que esta vez, por reverencia de la persona de don Pedro, obispo de Burgos (luego cardenal de Santa Sabina), por la mucha ayuda que de él había recibido en la corte de Roma, no quería hacerlo pero protestó que por esta razón no venga perjuicio a él o a su iglesia o sus sucesores.

Signatura: X.8.B.1.1

\section{1.- 1344, octubre 15. Compostela}

Don Pedro, arzobispo de Compostela y su cabildo conceden especial licencia en forma amigable a don Gil de Albornoz, arzobispo de Toledo, para que éste pueda llevar ante sí la cruz alzada cuantas veces le sea necesario atravesar el territorio de su diócesis y el de sus sufragáneos, sin perjuicio de sus propios derechos

Signatura: X.8.C.1.5

\section{2.- 1379, julio 18. Villamayor}

Testimonio notarial de cómo don Pedro Tenorio, arzobispo de Toledo, ante el temor de males mayores e inducido por cartas apremiantes del rey que le convocaban a Burgos a tratar del cisma, protestó que no renunciaba al derecho de como primado le cometía de ir con la cruz alzada por Burgos y todo su obispado, pero en esta ocasión dejaba de hacerlo. Se incluye una carta abierta de don Gomez, arzobispo de Toledo, sobre la misma materia (1366, septiembre 6. Sansoles).

Signatura: X.8.B.1.2

\section{3.- 1428, marzo 30. Roma}

Letras apostólicas graciosas de Martín V Ex suscepte servitutis por las que declara que don Juan Martínez de Contreras y sus sucesores en el arzobispado de Toledo son primados y que la primacía se equipara a las prerrogativas de los patriarcas y por tanto tiene precedencia sobre los notarios apostólicos y todos los demás arzobispos (a no ser que sean primados o electores del Imperio), en las capillas pontificias, consistorios y concilios.

Signatura: X.7.A.4.2

\section{4.- 1431, enero 14. Ágreda}

Proceso canónico en el pleito que sobre la primacía de Toledo se entabló entre don Juan Martínez de Contreras, arzobispo de Toledo, y don Juan, obispo de Tarazona, sustanciado ante don Pedro de Bocanegra, canónigo de Cuenca, juez conservador de la primacía. Lleva numerosísimos documentos sobre la primacía de Toledo

Signatura: X.8.D.1.1 (Supl. 115)

55.- 1432, diciembre 15. Roma

Letras de Lucidus de Comitibus, cardenal de Santa María in Cosmedin, juez apostólico dado junto con el cardenal Angelottus Fuscus, cardenal de San Marcos, en el proceso que sobre la primacía de Toledo pende en Roma entre don Juan Martínez de Contreras, arzobispo de Toledo, y don Dalmacio de Mur, arzobispo de Zaragoza.

Signatura: X.8.D.1.2a

56.- 1433, marzo 4. Roma

Letras patentes de Angelottus Fuscus, presbítero cardenal de San Marcos, y Lucidus de Comitibus, cardenal 
diácono de Santa María in Cosmedin, por las que intiman a todas las autoridades eclesiásticas de las diócesis y provincias de Toledo, Zaragoza y Tarragona que observen el mandato del papa Eugenio IV, el cual en consistorio de cardenales ha suspendido el proceso que pende en Roma entre don Juan Martínez de Contreras, arzobispo de Toledo, y don Dalmacio de Mur, arzobispo de Zaragoza, sobre el negocio de la primacía.

Signatura: X.8.D.1.2

\section{7.- 1448 , septiembre 12. Burgos}

Testimonio notarial de cómo don Pedro García de Huete, arcediano de Sigüenza, mayordomo mayor de don Alonso Carrillo y en nombre del deán y Cabildo de Toledo, pidió que se levantara acta de que el dicho arzobispo venía con el rey desde la villa de Navarrete hasta Burgos con la cruz alzada, sin contradicción alguna de don Alfonso García de Santamaría, obispo de Burgos, en presencia de numerosos testigos eclesiásticos y seglares.

Signatura: X.8.B.1.3

\section{8.- 1448, agosto 19. Burgos}

Don Pedro Fernández Carrillo, prior de la Catedral de Córdoba, juez subejecutor de unas letras apostólicas de Martín V, manda a todas las autoridades eclesiásticas y civiles de Burgos que habían promulgado entredicho en Burgos por ir don Alonso Carrillo con la cruz alzada, que levanten dicha pena y guarden al arzobispo todas las prerrogativas que como primado le corresponden, amenazándoles con penas canónicas.

Signatura: X.8.B.1.3a

\section{9.- 1448, agosto 20. Navarrete}

Carta de Juan II de Castilla al concejo, asistentes, alcaldes y demás autoridades civiles de Burgos, prohibiéndoles que se entrometan en el pleito existente entre don Alonso Carrillo, arzobispo de Toledo y don Alfonso García de Santamaría, obispo de Burgos, con motivo de haber entrado el arzobispo en dicha ciudad con la cruz alzada y que le permitan entrar así libremente en la ciudad.

Signatura: X.8.B.1.4a

\section{0.- 1448, agosto 20. Navarrete}

Carta de Juan II de Castilla a don Alfonso García de Santamaría, obispo de Burgos, mandándole que alce el entredicho impuesto en la ciudad con motivo de la entrada de don Alonso Carrillo, arzobispo de Toledo con la cruz alzada y que guarde el honor y la preeminencia que a dicho prelado le competen como a primado, pues así ha sido decretado por unas bulas apostólicas de Martín $\mathrm{V}$ a don Juan de Riaza, arzobispo de Toledo, que fueron vistas en el Consejo real.

Signatura: X.8.B.1.4

\section{1.- 1451, febrero 21. Valladolid}

Carta de Juan II de Castilla en que manda a todas las justicias seglares de Burgos y de las demás ciudades y villas de sus reinos que reconozcan a don Alonso Carrillo, arzobispo de Toledo, el derecho a llevar la cruz alzada por sus territorios en señal de primado.

Signatura: X.8.G.1.4
62.- 1453, junio 10. Escalona (en el campamento real)

Acta del consenso habido entre don Alfonso Carrillo, arzobispo de Toledo, y don Alfonso García de Santamaría, obispo de Burgos, por la que renuncian a la lite pendiente en Roma, mediante la cual llegan a la avenencia de que el arzobispo de Toledo reconoce a Burgos como diócesis sufragánea de Roma y exenta de metropolitano, y el de Burgos acepta que el de Toledo pueda pasar por la diócesis y obispado de Burgos con la cruz alzada, en señal de primado y patriarca de España.

Signatura: X.8.B.1.6a

\section{3.- 1453, agosto 11. Burgos}

El cabildo de Burgos acepta la concordia hecha entre don Alfonso Carrillo, arzobispo de Toledo y don Alfonso García de Santamaría, en la causa que pendía en Roma sobre el derecho de primacía del toledano sobre Burgos, la cual concordia se incluye, en virtud de la cual al arzobispo de Toledo le era reconocido el derecho a llevar la cruz alzada en Burgos y al de Burgos se le reconocía su calidad de diócesis exenta.

Signatura: X.8.B.1.6

64.- 1489, mayo 2. Roma

Letras apostólicas graciosas de Inocencio VIII «Solet et provida», dirigidas a don Pedro González de Mendoza, arzobispo de Toledo y Cardenal de Santa Cruz, concediéndole que, mientras se ventila el pleito entre él y el arzobispo de Braga, pueda ejercer todos los derechos y jurisdicción que le corresponden como primado, en los reinos de Castilla y León.

Signatura: X.7.A.4.5

\section{- Fondo de Obra y Fábrica}

Para el mismo aconsejamos acudir al Catálogo realizado por Carmen Torroja en 1977 y comentado con anterioridad. Aunque sólo publicado el primero de sus tomos, alcanza hasta el año 1600 y por tanto toda la época medieval.

\section{- Biblioteca Capitular}

Multitud de libros manuscritos e impresos se encuentran entre sus fondos, con tratados teológicos, constituciones, ceremoniales,... que pueden localizarse en los diferentes catálogos publicados mencionados.

Entre los manuscritos (no incluimos los impresos ya que hay un catálogo publicado por el personal del archivo referido a los mismos, al que ya hicimos referencia) para una historia institucional de la Iglesia de Toledo destacan:

\section{- Signatura 23-16}

Hace referencia a las Constituciones de la Iglesia de Toledo de los años 1291, 1296, 1302, 1322, 1323, 1324, 1325 y 1326 . Son textos tanto en latín como en castellano. Tiene 51 folios.

\section{- Signatura 23-17}

Incluye las Constituciones de la Iglesia de Toledo de los años 1357, 1388, 1425, 1431, 1462, 1468, 1489 y 1539. Son textos tanto en latín como en castellano. Tiene 82 folios (algunos están marcados como «bis») de constituciones, aunque 
con sello de tinta se marcan (numeración por cada cara del folio) desde el 1 al 132, llegando hasta constituciones de 1531. Después de la numeración vienen otros, pero ya de mediados del XVI, y fuera del ámbito medieval. Los medievales con esta numeración a una cara, llegan del folio 1 al 105.

\section{- Signatura 23-18}

Es una copia incompleta del manuscrito anterior, realizada en el siglo XVIII. De hecho así se hace saber en las primeras páginas del libro: «Constitutiones Ecclesiae Toletanae / Constitutiones Ecclesiae Toletanae / Esta es una copia incompleta del libro / grande de Constituciones y está inme-/diato, asi escusamos, y escusa cualquiera / a cansarse en leerla, pues en el Libro / Grande están las constituciones de me-/jor letra». Tiene 92 folios escritos, por ambas caras, y copia los documentos de los folios 1-86 del 23-17 de forma completa. El documento, del cardenal Mendoza, de los folios 87-91 del libro 23-17 está copiado de forma incompleta.

\section{- Signaturas $27-21$ y $27-22$}

Corresponden respectivamente a los dos volúmenes manuscritos por Baltasar Porreño ${ }^{42}$ sobre la Historia de los Arzobispos de Toledo.

El primer volumen (con 286 folios) incluye desde San Eugenio Mártir, primer arzobispo de Toledo, a don Pedro Tenorio, catalogado como el septuagésimo sexto. El segundo volumen (con 300 folios) desde don Pedro de Luna, septuagésimo séptimo arzobispo de Toledo, hasta don Bernardo de Sandoval de Rojas, nonagésimo tercero.

Ambos tomos se dividen en capítulos, siendo generalmente cada uno de ellos el dedicado a un arzobispo. Debajo del epígrafe de cada arzobispo, que se detalla con su nombre completo y el número que ocupa en la sucesión de metropolitanos toledanos, se indica bajo qué rey/reyes de Castilla o de España ejerció su pontificado el prelado. En el texto de todos los capítulos, en los márgenes, suele haber nuevos epígrafes que sirven de subcapítulos o apartados (en muchos casos, es la marca de cuando un nuevo año comienza). En muchos casos hay datos generales sobre la Historia de España o sobre las biografías de los monarcas castellanos o españoles, más que sobre los propios prelados.

Al final de la vida de cada arzobispo, tras anunciar su muerte, suele hacerse relación de otros hombres notables que han vivido en su tiempo, especialmente santos, hombres de letras,...

\section{- Signatura 27-27}

Bajo el título Apuntaciones para la Historia de Toledo y sus Arzobispos con epitafios, y como su propio nombre indica, son anotaciones, esto es, nada redactado, sino un borrador de lo que luego se pensaba realizar un libro.

\section{- Signatura 38-25}

Libro de principios del siglo XIV relacionado con diversas acciones del arcediano de Toledo, el maestro Jofré de Loaysa. Destaca una reorganización de las parroquias de la ciudad de Toledo en dicha época. (1946).

42 Su vida y obra fue estudiada por Juan Francisco Rivera Recio

\section{- Signatura 42-20}

Bajo el título Liber privilegiorum ecclesiae Toletanae incluye diversos privilegios de la sede toledana, comenzando con la donación de Alfonso VI en 1086 y el último está fechado en 1187.

\section{- Signatura 42-21}

Bajo el título Liber privilegiorum de primatus ecclesiae Toletane está compuesto por las diferentes bulas de confirmación de la Primacía para el prelado toledano. Fue compuesto en torno a la segunda década del siglo xIII (el último de los documentos es la confirmación de Honorio III del 20 de febrero de 1217), basados en los documentos que se conservaban en el registro vaticano. Seguramente fue elaborado por orden de Jiménez de Rada para y durante la asistencia al IV Concilio de Letrán, donde se trató el tema de la primacía.

\section{- Signatura 42-22}

En torno al epígrafe Liber privilegiorum super primatu Toletane Ecclesie es similar al anterior, elaborado en torno a 1219 y 1231 con añadidos de 1241 y 1251, y recogiendo los registros de forma similar al 42-21. Es probablemente compuesto para un nuevo pleito que se desarrollaría en la curia pontificia con la sede compostelana. Recogería lo omitido en el anterior y añadiendo lo nuevo desde entonces. El último documento es una carta de Inocencio IV en mayo de 1251 en el que nombraba al infante Sancho como administrador temporal y espiritual de Toledo.

\section{- Signatura 42-23}

Lleva por título Liber priuilegiorum ecclesie toletane. En los folios preliminares (d-f) y a tres columnas está en rojo con iniciales moradas el índice de los documentos, nombrándose unos 300, aunque hay unos 500 allí contenidos.

La colección tiene varias partes:

1. Traslado de privilegios reales ${ }^{43}$, donaciones, contratos y acuerdos.

2. Inventario de los objetos de culto de la catedral.

3. Traslado de bulas pontificias.

4. Traslado del pleito surgido entre Toledo y Tarragona, no sobre la primacía, a pesar de lo que dice el Repertorio, sino sobre la jurisdicción arzobispal sobre la diócesis de Valencia.

\section{- Signatura 42-29}

Conocido como Libro de Arcayos, incluye diversos asuntos de la Iglesia de Toledo escrito por un racionero de la misma en el siglo XVII. En la Biblioteca existen dos ejemplares, uno es el original del siglo XVII, con adiciones en las páginas, y otro es copia del siglo XVIII en dos tomos. La copia del XVIII, en su primera página, anuncia que fue mandada escribir por acto capitular del 13 de septiembre de 1765, y se hizo por la difícil comprensión de la letra y malos márgenes, con idea de pasarlo a limpio.

Recibe el nombre por Juan Chaves de Arcayos que, según la primera página de la copia del XVIII, era repartidor del coro de la Catedral de Toledo y racionero de la misma entre 1589 y 1643.

\footnotetext{
43 Estudiados en Rivera Recio 1948.
} 
Su información es enorme, sobre todo para conocer la vida de la Catedral en la Edad Moderna (cómo se realiza la posesión de una canonjía, cuales son, quiénes la ocupan, diversos ceremoniales,...), aunque es interesante porque hay noticias y referencias de época medieval. Hay información de fiestas, cargos, actos capitulares, testamentos, capeIlanías,... Copia además información de otros libros, como los de constituciones del cabildo (23-16, 23-17 y 23-18).

\section{- Signaturas 42-30, 42-31, 42-32, 42-34}

Diversos calendarios de fiestas y aniversarios de la Catedral de Toledo. Interesante para conocer su existencia y forma, ya que en muchos casos explica cómo deben hacerse y la categoría que poseen (número de capas), además de las distribuciones que se repartían entre los asistentes a ellas.

Finalizamos aquí, dejando constancia de un hecho: el Archivo Capitular toledano está aún poco explotado pese a la importancia y riqueza documental que contiene: 11.000 pergaminos, 90 libros de actas capitulares y 1.500 piezas en el Archivo de Obra y Fábrica de la Catedral.

\section{BIBLIOGRAFÍA}

Arellano García, M. 1984. Catálogo del Archivo del Cabildo de curas y beneficiados de Toledo. Toledo.

Asanza, M. G. y Núñez Clemente, G. 1924. Clero secular y regular: Inventario de procedencias. Valladolid.

Ballesteros San José, P. et al. 1995. «Documentación medieval en los archivos municipales de Castilla-La Mancha». Espacios y fueros en Castilla-La Mancha (siglos XI-XV): una perspectiva metodológica: 509-594.

Cruz Arias, M. J. 2004. Documentación procedente de cofradías y hermandades en el Archivo de la Diputación de Toledo: 361-369. Toledo: Diputación Provincial.

Fernández Catón, J. M.a 1989. «Documentos del archivo de la Catedral de Toledo en escritura visigótica». Estudios sobre Alfonso VI y la Reconquista de Toledo: 61-106. Toledo: Instituto de Estudios Visigótico-Mozárabes.

Fernández Collado, Á. 2007. Guía del Archivo y Biblioteca Capitulares de la Catedral de Toledo. Toledo: Instituto Teológico de San Ildefonso.

Fernández Collado, Á., Rodríguez González, A. y Castañeda Tordera, I. 2007. Catálogo del Archivo de la capilla de San Pedro en la Catedral de Toledo. Toledo: Instituto Teológico de San Ildefonso.

Fernández Collado, Á., Rodríguez González, A. y Castañeda Tordera, I. 2009. Catálogo de impresos de la Catedral de Toledo. Toledo: Instituto Teológico de San Ildefonso.
García García, A. y Gonzálvez Ruiz, R. 1970. Catálogo de los manuscritos jurídicos medievales de la Catedral de Toledo. Madrid: CSIC.

García Luján, J. A. 1982. Privilegios reales de la Catedral de Toledo (1086-1462). Toledo: Caja de Ahorro Provincial.

García Ruipérez, M. 1997. "Los Archivos toledanos y las publicaciones de sus instrumentos de descripción». Ensayos Humanísticos. Homenaje al Profesor Luis Lorente Toledo: 209-232. Editorial de la Universidad de Castilla-La Mancha: Cuenca.

González Novalín, J. L. 2007. «El Archivo Secreto Vaticano y otros archivos de la Santa Sede: fuentes para la bibliografía/biografía eclesiástica». Memoria Ecclesie, 30: 395-412.

González Palencia, Á. 1926-1930. Los mozárabes de Toledo, siglos XIIXIII (4 volúmenes).

Gonzálvez Ruiz, R. 1997. Hombres y Libros de Toledo (1086-1300). Fundación Ramón Areces: Madrid.

Guglieri Navarro, A. 1974. Catálogo de los Sellos de la Sección de Sigilografía del Archivo Histórico Nacional, 3 vols. Madrid.

Hernández, F. J. 1996. Los cartularios de Toledo. Catálogo monumental. Fundación Ramón Areces: Madrid.

Janini, J. y Gonzálvez, R. 1977. Catálogo de los manuscritos litúrgicos de la catedral de Toledo. Diputación Provincial de Toledo: Toledo.

Janini, J. y Serrano, J. 1979. Manuscritos litúrgicos de la Biblioteca Nacional: Catálogo. Madrid.

Ladero Quesada, M. Á. y Nieto Soria, J. M. 1988. «Iglesia y sociedad en los siglos XIII al XV (ámbito castellano-leonés). Estado de la Investigación». En la España medieval, 11: 125-151.

León Tello, P. y De la Peña, M. T. 1950-1952. Guía de las Sección de Códices, 2 vols. Madrid.

Lop Otín, M.a J. 2002. El cabildo catedralicio de Toledo en el siglo $x V$ : aspectos institucionales y sociológicos. Madrid: Universidad Complutense (Tesis doctoral).

Martí Bonet, J. M.a (dir.) 1985. Guía de los Archivos de la Iglesia en España. León: Asociación Española de Archiveros Eclesiásticos. Disponible en http://www.mcu.es/archivos/docs/Archivoslglesia.pdf

Octavio de Toledo, J. M. 1903. Catálogo de la Librería del Cabildo toledano. Madrid

Rivera Recio, J. F. 1946. «Baltasar Porreño (1569-1639). Historiador de los Arzobispos de Toledo». Boletín de la Real Academia de Bellas Artes y Ciencias Históricas de Toledo, 60: 107-138.

Rivera Recio, J. F. 1948. "El 'Liber privilegiorum' de la catedral de Toledo y los documentos reales en él contenidos». Hispania Sacra, 1: $163-182$

Rivera Recio, J. F. 1950. Guía del Archivo Capitular de la Catedral de Toledo. Madrid: Dirección General de Archivos y Bibliotecas.

Sánchez Benito, J. M. 1999. Colección de documentos de la Santa Hermandad: 1300-1500. Toledo: Diputación Provincial.

Torroja Menéndez, C. 1977. Catálogo del Archivo de Obra y Fábrica de la Catedral de Toledo. Tomo I. Toledo: Instituto Provincial de investigaciones y estudios toledanos.

Villalba Ruiz de Toledo, F. J. 1999. Colección diplomática del cardenal Mendoza (1454-1503). Disponible en: https://www.uam.es/ departamentos/filoyletras/hmedieval/especifica/cuadernos/coldoc/cd1.pdf 